\title{
Evidence of the origin of the gelatinous masses in the oviducts of mares
}

\author{
Y. Tsutsumi, H. Suzuki, T. Takeda and Y. Terami \\ Department of Animal Science, Faculty of Agriculture, Hokkaido University, Sapporo 060, \\ Japan
}

\begin{abstract}
Summary. The gelatinous masses known to occur in the mare oviduct were examined by light and scanning electron microscopy. Many (44\%) of the masses which occurred in 16 of the 24 oviducts studied were connected with the mucosa of the ampulla near the ampullary-isthmic junction. The masses consisted of lobules of fine fibres probably derived from the fibrous connective tissue of the lamina propria in the oviductal mucosa.
\end{abstract}

\section{Introduction}

Since the initial report by van Niekerk \& Gerneke (1966), it has been confirmed by many investigators that unfertilized ova are retained and accumulate for a considerable period in the ampullary-isthmic junction of the oviduct in the mare (Oguri \& Tsutsumi, 1972; Onuma, Matsuoka, Nakamura, Nakanishi \& Fujishiro, 1972; Steffenhagen, Pineda \& Ginther, 1972; Betteridge \& Mitchell, 1974, 1975; David, 1975; Onuma \& Ohnami, 1975; Betteridge, Flood \& Mitchell, 1976; van Niekerk, 1976; Webel, Franklin, Harland \& Dziuk, 1977). Globular gelatinous masses, which were also originally reported by van Niekerk \& Gerneke (1966), are frequently found in the ampullary portion near the isthmic junction in the mare (Oguri \& Tsutsumi, 1972; Onuma et al., 1972; Onuma \& Ohnami, 1975). Although the above observations strongly suggest that fertilized eggs may bypass old unfertilized eggs retained in the oviduct, the mechanism which leads to such differential transport of fertilized eggs remains obscure. It is possible that the globular gelatinous masses in the oviduct may play some role in the retention of the unfertilized eggs in the oviduct, but the origin of the masses has not yet been determined.

Van Niekerk \& Gerneke (1966) and van Niekerk (1976) observed that the ovum was enclosed in a large irregular gelatinous mass of follicular origin immediately after ovulation and that the ovum was separated from this mass by condensation during the second day. Oguri \& Tsutsumi (1972) confirmed that recently ovulated ova are encased in a gelatinous mass of follicular origin in the oviduct, but Onuma et al. (1972) and Onuma \& Ohnami (1975) claimed that the gelatinous masses were derived from desquamated cells of the tubal mucosa because the masses consisted of collagen fibres and contained various degenerated cells, probably from the tubal mucosa.

However, in a study of the transport of fertilized equine eggs through the oviduct (Y. Tsutsumi, unpublished observation) it was noted that some globular gelatinous masses were connected with the oviductal mucosa, apparently confirming a mucosal origin for the mass. In the present study an attempt was made to clarify the origin of the gelatinous masses in the equine oviduct.

\section{Materials and Methods}

A total of 22 oviducts of 11 mares ( 7 Hokkaido native ponies, 2 hybrid horses and 2 race horses ranging from 2 to 22 years in age) were obtained immediately after killing at a slaughterhouse in 
April. In the first group, 18 oviducts of 9 mares were trimmed and straightened after transportation to the laboratory. The oviducts were immersed in a physiological saline solution $(9 \mathrm{~g} \mathrm{NaCl} / \mathrm{l})$, slit longitudinally and the globular gelatinous masses were located in the lumen by the aid of a dissecting microscope. Four oviducts of 2 mares were subjected to a similar procedure immediately after killing at the slaughterhouse, and some pieces of the oviductal mucosa and the globular gelatinous masses were placed in $3 \%$ glutaraldehyde in $0.1 \mathrm{M}$-phosphate buffer ( $\mathrm{pH} \mathrm{7.4)}$ at $4^{\circ} \mathrm{C}$ for histological and scanning electron microscopic investigations.

The lengths of the ampullary and isthmic portions of the oviduct were measured, and the positions, sizes and shapes of the globular gelatinous masses were recorded. The status of the ovaries was checked also. The masses obtained free from the oviductal lumen and the masses connected with the oviductal mucosa, together with part of the mucosa, were fixed in the $3 \%$ glutaraldehyde solution described above for histological and scanning electron microscope investigations. The oviducts of a mare (race horse) which were obtained previously and stored in $10 \%$ formalin solution were used additionally; one oviduct for histology and the other for locating the masses.

For histological purposes, paraffin-wax sections were cut at 7-10 $\mu \mathrm{m}$ and stained with haematoxylin and eosin, Azan, Gomori's trichrome, PAS or aldehyde-fuchsin. For scanning electron microscopy, specimens were rinsed in $0.1 \mathrm{M}$-phosphate buffer after prefixation and postfixed in $1 \% \mathrm{OsO}_{4}$ in $0.1 \mathrm{M}$-phosphate buffer. After fixation, the tissues were rinsed and dehydrated in increasing concentrations of ethanol and then dried using $\mathrm{CO}_{2}$ and isoamyl acetate as the intermediate fluid in a critical-point drying apparatus. The dried portions of tissue were coated in approximately $200 \AA$ thickness of gold by the spattering mode using an Ion Coater (Model IB-3, Eiko Engineering). An Hitachi S-310 Scanning Electron Microscope operating at 5 $\mathrm{kV}$ accelerating voltage was used in the examination.

\section{Results}

The masses were grayish white and easily recognizable under the dissecting microscope. The masses varied in shape and size; some were thread-like masses $(3.5-7.5 \mathrm{~mm}$ in length and 1-1.2 $\mathrm{mm}$ in width), others were globular masses (1-1.5 $\mathrm{mm}$ in diameter). Some of the thread-like masses had branches. The masses were obtained from 16 of 24 oviducts $(67 \%)$ and it was noted that all of them were located in the ampullary portion of the oviducts (Text-fig. 1), most (78\%) being near the ampullary-isthmic junction. In 7 out of 16 oviducts with the masses (44\%), the masses were connected with the oviductal mucosa; at least 5 of the masses were clearly connected with the mucosa at one point, and 2 of them were connected by a narrow string (Pl. 1, Fig. 4). Such masses connecting with the mucosa were located only in the area near the junction (Text-fig. 1).

\section{PLATE 1}

Fig. 1. Cross-section of the fibrous mass located in the ampullary portion of the oviduct. Azan stain, $\times 160$.

Fig. 2. Scanning electron micrograph of the mass showing its structure of many lobules of various sizes.

Fig. 3. Higher magnification of the surface of the mass. The mass has no epithelium and consists of fine fibres.

Fig. 4. Scanning electron micrograph showing the connection between the mass and the mucosa by a thin string.

Fig. 5. Photomicograph of the connection between the mass and the mucosa. Bundles of fibres are seen entwined and penetrating the lamina propria. Haematoxylin-eosin stain, $\times 200$. 

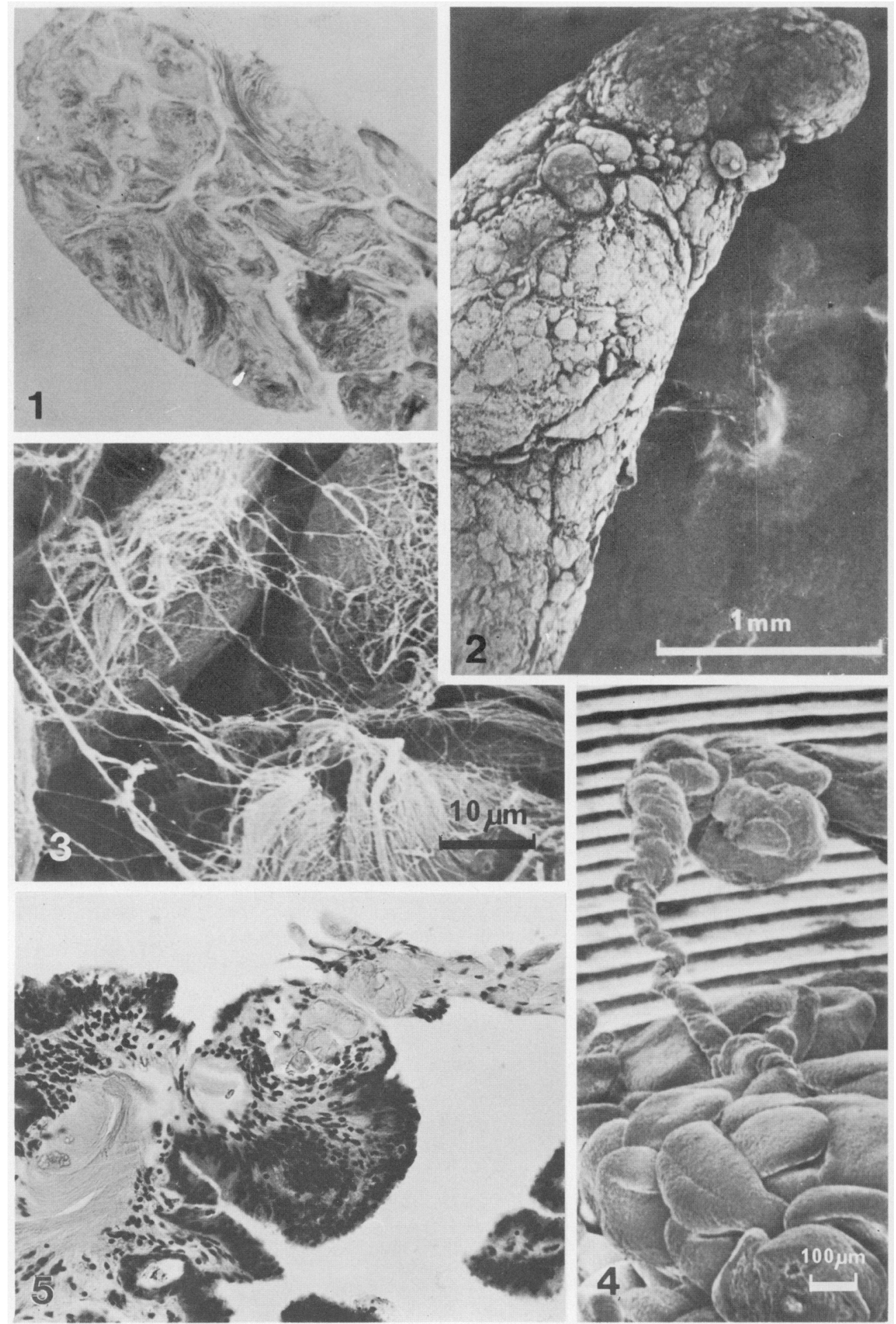


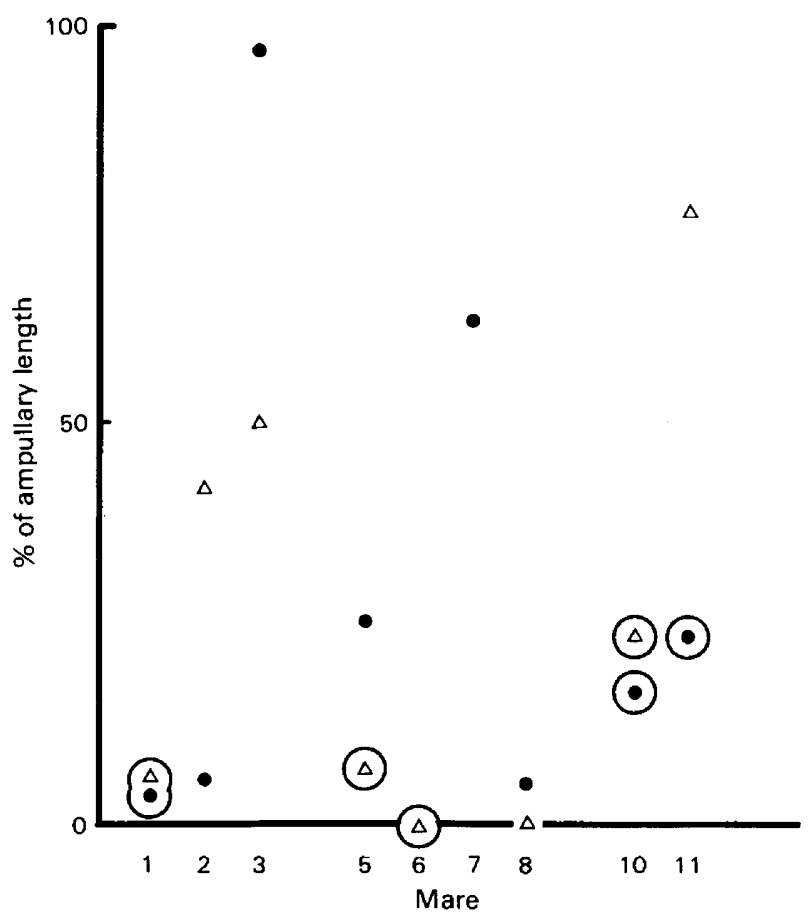

Text-fig. 1. Locations of the gelatinous masses in the ampullary portion of the oviduct in each mare: $0=$ ampullary-isthmic junction, $100=$ abdominal ostium. 0 , Mass in the right oviduct; $\triangle$, mass in the left oviduct; $O$, mass connected to the oviductal mucosa.

Histological observations of the masses showed that they were formed by many lobules of various sizes and were constructed of swirling bundles of fine fibres ( $\mathrm{Pl}$. 1, Figs 1 and 5). The bundles were stained weakly with eosin, blue with Azan stain, green with Gomori's trichrome stain, and light red with PAS. These results strongly suggested that the masses consisted of collagen fibres. In one of the masses (PI. 1, Fig. 5) a thin string of the mass was twisted and appeared to be penetrating the mucosa through the epithelium, where the fibrous structure of the mass was transformed into the fibrous connective tissue of the lamina propria. However, there were no special features noted histologically in the mucosa surrounding the area giving rise to the fibres of the mass. There was no epithelium on the surface of the masses and only a few degenerating nuclei of fibroblasts could be seen embedded in the masses, mainly located on the surface of the lobules. Elastic fibres could not be demonstrated in the masses by the aldehydefuchsin stain.

Scanning electron microscopic studies of the masses confirmed the lobular structure of the masses (Pl. 1, Fig. 2) and the consistency of fine fibres (PI. 1, Fig. 3). The structure of free and attached masses was similar in observations with light and scanning electron microscopy, indicating that both types of mass have a similar origin.

\section{Discussion}

Globular gelatinous masses were found in $87 \%$ of 135 oviductal flushings by Oguri \& Tsutsumi (1972) and in $76.2 \%$ of 424 flushings by Onuma \& Ohnami (1975). The detection of the masses in the present study (67\%) was low compared with the above 2 reports, and this may be due to the limited number of oviducts. The masses in $44 \%$ of the oviducts containing these bodies 
were connected with the oviductal mucosa, indicating that the phenomenon may be common and widespread in the oviduct of the mare.

Two opinions have been presented as to the origin of the masses; namely, the follicular origin (van Niekerk \& Gerneke, 1966) and the oviductal mucosal origin (Onuma et al., 1972; Onuma \& Ohnami, 1975). Flood, Jong \& Betteridge (1979) have questioned the histological findings of Onuma et al. (1972) and Onuma \& Ohnami (1975) that the masses consist of collagen fibres from the desquamated oviductal mucosa, but admit that a follicular origin cannot be discounted. However, there are some contradictions for the follicular origin hypothesis: some masses have been recovered from oviducts associated with ovaries which have not ovulated (Oguri \& Tsutsumi, 1972), and unfertilized eggs have never been found in the masses, although newly ovulated eggs are enveloped by a viscous and elastic mass of follicular origin. The results of the present study clearly show that the masses originate from the oviductal mucosa. As the mass consists of bundles of fibres, the gelatinous mass may be referred to as a fibrous mass. Distribution of the masses in the ampullary portion showed that all masses connected to the mucosa are located near the ampullary-isthmic junction and the masses which are free in the lumen are scattered throughout the ampulla, indicating transportation of the masses through the ampulla. However, the process of formation and the functional role of the masses are still unknown.

This work was supported in part by a Research Project Grant (Project No. 348063) from the Ministry of Education, Japan.

\section{References}

Betteridge, K.J. \& Mitchell, D. (1974) Direct evidence of retention of unfertilized ova in the oviduct of the mare. J. Reprod. Fert. 39, 145-148.

Betteridge, K.J. \& Mitchell, D. (1975) A surgical technique applied to the study of tubal eggs in the mare. J. Reprod. Fert., Suppl. 23, 519-524.

Betteridge, K.J., Flood, P.F. \& Mitchell, D. (1976) Possible role of the embryo in the control of oviductal transport in mares. In Ovum Transport and Fertility Regulation, pp. 381-389. Eds M. J. K. Harper, C. J. Pauerstein, C. E. Adams, E. M. Coutinho, H. B. Croxatto \& D. M. Paton. Scriptor, Copenhagen.

David, J.S.E. (1975) A survey of eggs in the oviducts of mares. J. Reprod. Fert., Suppl. 23, 513-517.

Flood, P.F., Jong, A. \& Betteridge, K.J. (1979) The location of eggs retained in the oviducts of mares. J. Reprod. Fert. 57, 291-294.

Oguri, N. \& Tsutsumi, Y. (1972) Studies on lodging of the equine unfertilized ova in Fallopian tube. Res. Bull. Livestock Farm, Hokkaido Univ. 6, 32-43.
Onuma, H. \& Ohnami, Y. (1975) Retention of tubal eggs in mares. J. Reprod. Fert., Suppl. 23, 507-511.

Onuma, H., Matsuoka, K., Nakamura, Y., Nakanishi, H. \& Fujishiro, T. (1972) Intra-oviductal retention of the eggs of mares. Jap. J. vet. Sci. 34, 166-167.

Steffenhagen, W.P., Pineda, M.H. \& Ginther, O.J. (1972) Retention of unfertilized ova in uterine tubes of mare. Am. J. vet. Res. 33, 2391-2398.

van Niekerk, C.H. (1976) Retention of unfertilized ova in the oviduct of mares. In Ovum Transport and Fertility Regulation, pp. 375-380. Eds M. J. K. Harper, C. J. Pauerstein, C. E. Adams, E. M. Coutinho, H. B. Croxatto \& D. M. Paton. Scriptor, Copenhagen.

van Niekerk, C.H. \& Gerneke, W.H. (1966) Persistence and parthenogenetic cleavage of tubal ova in the mare. Onderstepoort J. vet. Res. 33, 195-232.

Webel, S.K., Franklin, V., Harland, B. \& Dziuk, P.J. (1977) Fertility, ovulation and maturation of eggs in mares injected with HCG. J. Reprod. Fert. 51, 337341.

Received 24 October 1978 